\title{
HOW ARE TWITTER ACTIVITIES RELATED TO TOP CRYPTOCURRENCIES' PERFORMANCE? EVIDENCE FROM SOCIAL MEDIA NETWORK AND SENTIMENT ANALYSIS
}

\author{
Han Woo PARK \\ Yeungnam University, Gyeong-san, Republic of Korea \\ Youngioo LEE \\ National Informatization Agency, Daegu, Republic of Korea \\ UDK: 077.5 \\ Izvorni znanstveni rad
}

Primljeno: 28. 7. 2018.

Cryptocurrencies have embraced Twitter as a major channel of communication. Employing social network analysis and sentiment analysis, this study investigates the Twitter-mediated communication behaviors among cryptocurrencies. This study determines whether a significant association exists between cryptocurrencies' Twitter networks and their credit scores. Data were drawn from the Twitter pages of several top cryptocurrencies. The results indicate that reply-mention networks had the densest structure, that the following-follower network structure was correlated with the reply-mention structure, and that the reply-mention and co-tweet networks were positively correlated. The results also indicate that cryptocurrencies' active networking strategies affected their credit scores and more importantly, that cryptocurrencies frequently linked with fellow currencies tended to have high credit scores.

Keywords: cryptocurrency, Twitter, social network analysis, Weiss rating, sentiment analysis

Han Woo Park, Media \& Communication, Digital Convergence Business, Yeungnam University, 280 Dae-hak-ro, Gyeong-san, South Korea, Zip code 38541. 
According to the global macro research team of Goldman Sachs (2018), the spectacular rise and fall of bitcoin and alternative cryptocurrencies (also called "altcoins") has been sufficiently transformative to attract investment. In other words, cryptocurrencies are now at the top of the market's mind. To explain this surging market, Goldman Sachs quotes Shiller (2000), who, in Irrational Exuberance, describes a "situation in which news of price increases spurs investor enthusiasm which spreads by psychological contagion from person to person, in the process amplifying stories that might justify the price increase and bring in a larger and larger class of investors, who, despite doubts about the real value of the investment, are drawn to it partly through envy of others' successes and partly through a gambler's excitement." One of the main drivers of the bitcoin and altcoin boom is, indeed, a social contagion, or social influence.

Social media affects our lives every day, but it also has a huge impact on market prices of cryptocurrencies and their fluctuations. News, comments, and official updates of cryptocurrencies via social media seem to spread by word-of-mouth and formulate people's decisions to buy or sell certain crypto-currencies (Garcia, Tessone, Mavrodiev, \& Perony, 2014). Indeed, people who are interested in and holding bitcoin can get any information available about it via Twitter, Facebook, and Reddit. Moreover, almost all cryptocurrency companies are using social media as an advertising tool by frequently announcing their software upgrades, holding seminars, and other activities that might make people believe something great is happening. On the other hand, Weiss Rating, an independent securities rating agency, is the most conspicuous influence in cryptography evaluation and claims to offer the first "ratings on cryptocurrencies." It seems that this agency's ratings often differ from the general popularity of the coins, as investors are not confident about the validity and objectivity of ratings, and are suspicious about the agency's expertise in cryptocurrency and blockchain technology (Veloff, 2018).

This confusion implies that assessing the socio-economic impact and future value of emerging technologies is complex and multidimensional. One might also raise questions about whether it is reasonable to rely solely on a single source and traditional standards for evaluating cryptocurrencies. In this study, we argue that the influence of some emerging technologies on social media should also be regarded as one of the measures of future value. To support this argument, we quantify the interactions among cryptocurrencies in the social media through social network analysis and explore the relationship with their actual performance. More specifically, we explore the strengths and weaknesses of cryptocurrencies as 
DRUŠ. ISTRAŽ. ZAGREB GOD. 28 (2019), BR. 3, STR. $435-460$

PARK, H. W., LEE, Y.: HOW ARE TWITTER... perceived by their peers. We propose that the value of a cryptocurrency may be determined according to whether it is an active networker and/or authoritative hub on social media and whether its networked position is reflected in the market price. Moreover, we focus on the discourse in the social media about the prosperity of cryptocurrency and its changes over time. Thus, the present study takes a multidimensional approach employing social network analysis and sentiment analysis to examine the social communication system in the cryptocurrency agenda.

\section{LITERATURE REVIEW}

\section{Cryptocurrency as a new paradigm}

Cryptocurrency is defined as "a digital asset that is constructed to function as a medium of exchange, premised on the technology of cryptography, to secure the transactional flow, as well as to control the creation of additional units of the currency" (Chohan, 2017). In the general public, cryptocurrencies are often referred to as virtual currencies and sometimes alternative currencies. The main difference from previous digital currencies is that cryptocurrency is based on a decentralized control system, which is a digitally implemented distributed ledger, as opposed to a centralized banking system (Narayanan, Bonneau, Felten, Miller, \& Goldfeder, 2016). The blockchain technology that enables this decentralization is an overall technology in which multiple computers simultaneously record and verify currency issuance and transaction history on a peer-to-peer distributed network using a hash algorithm (Yli-Huumo, Ko, Choi, Park, \& Smolander, 2016). The idea is that transactions are not stored in a centralized or unified place, but everyone who participates shares the same copy to work with as certification and is agreed to by the majority in the network.

The notion of cryptocurrency officially appeared in the world when Satoshi Nakamoto (2008) released the essay "Bitcoin: A Peer-to-Peer Electronic Cash System." On January 3, 2009, when Nakamoto "mined" the first bitcoin, the world's first and largest decentralized cryptocurrency emerged. Although cryptography was referred to in several technical documents before Nakamoto (2008), there seems to be a consensus to regard bitcoin as the pioneer of cryptocurrency (Swan, 2015; Lu, Yang, L.-W., Lin, Yang, T.-H., \& Chen, 2017; Yli-Huumo et al., 2016). Shortly after the appearance of bitcoin, people wanted a new feature that would allow them to move beyond simple peer-to-peer transactions. Cryptocurrency developers began to devise a way to "paint" an additional attribute on a bitcoin. The result is called a "colored coin" or "token," which records 
DRUŠ. ISTRAŽ. ZAGREB GOD. 28 (2019), BR. 3, STR. $435-460$

PARK, H. W., LEE, Y.: HOW ARE TWITTER...

\section{Research trends on blockchain and cryptocurrencies}

In their comprehensive review of the current research on blockchain technology, Yli-Huumo et al. (2016) collected 41 key publications using six scientific databases: IEEE Xplore, ACM Digital Library, Springer Link, ScienceDirect, Ebscohost, and PLOS One. Their findings indicate that blockchain papers have been published since 2012 and peaked at 16 papers (39\%) in 2014 and 23 papers $(56 \%)$ in 2015 . It is noteworthy that, while the 2014 papers focus on blockchain improvements, suggesting new solutions for the current technology, the 2015 papers shift- 
DRUŠ. ISTRAŽ. ZAGREB GOD. 28 (2019), BR. 3, STR. 435-460

PARK, H. W., LEE, Y.: HOW ARE TWITTER.. ed to a discussion of blockchain applications, including bitcoin. Another recent review of the blockchain and cryptocurrency literature studied 190 documents and revealed that the number of publications jumped from 14 documents in 2014 to about 100 in 2017 (Brandão, Mamede, \& Gonçalves, 2018). While about $40 \%$ of those publications dealt with bitcoin, other studies dealt with the new integration of blockchain technology for the Internet of Things-mediated smart cities (about 30\% of papers), finance/contracts (about 15\%), and electronic government (about 12\%).

Thus, the existing literature on cryptocurrency and blockchain technology is mostly about engineering issues (e.g., Marsal-Llacuna, 2017). In social science research, only a few financial institutes and universities have started to study the social recognition and acceptance of cryptocurrency and blockchain technology. The Bank of Canada selected 1,997 Canadians through systematic sampling and surveyed their bitcoin transaction activities (Henry, Huynh, \& Nicholls, 2017). As a result, about 64 percent of Canadians have heard of bitcoin, but only 2.9 percent have holdings. The percentage of awareness was higher in males than females, and in university graduates than lower-level graduates. Younger and more educated respondents owned more bitcoins than those who were older and less educated. The University of Cambridge published a report as a result of research on the global cryptographic industry (Hileman \& Rauchs, 2017). According to the report, the cryptocurrency industry consists of four sub-sectors: exchanges, wallets, settlements, and mining. Currently about 150 cryptographic companies across 38 countries are active in four sectors. The United States had the largest number of 32 companies, followed by China with 29 companies and the United Kingdom with 16 companies. The convergence of inter-enterprise services is rapidly progressing among companies from different industries.

Literature in the financial sector has discussed whether bitcoin and blockchain will change the existing economic system and lead to destructive innovation (Wörner et al., 2016; Friedlmaier, Tumasjan, \& Welpe, 2017). These researchers focus on the potential of the open source policy and distributed peer-to-peer network, and note that with this business model, startup companies can easily penetrate the existing market. Finally, in terms of the efficiency of the financial system, research has been conducted on methods for solving financial fraud, tax evasion, and double taxation using block chain technology (Hyvärinen, Risius, \& Friis, 2017). As Hayes (2017) stated in his survey of relevant literature on bitcoin and its cousins, a small number of studies in social sciences have attempted to 
DRUŠ. ISTRAŽ. ZAGREB GOD. 28 (2019), BR. 3, STR. $435-460$

PARK, H. W., LEE, Y.: HOW ARE TWITTER... investigate the monetization of blockchain. In response, he conducted an empirical valuation of the 66 most widely used bitcoins and altcoins using a regression model with production cost variables, including the level of competition in the network of producers, the rate of unit production, and the difficulty of the algorithm used to "mine" for the cryptocurrency.

\section{Cryptocurrency study using social media data}

Despite the growing need, even in academia, of exploiting social media to generate knowledge about the underlying behavior of social and economic agents (e.g. Redek \& Godnov, 2018; Blazquez \& Domenech, 2017), only a few studies have used a non-traditional analysis approach to observe the cryptocurrency market and public attention. Lu et al.'s (2017) review of journal papers, technical documents, and online forums that appeared from 2008 to 2016 was not limited to scholarly publications, and identified eight categories of blockchain literature: studies on monetary systems, currency, market confidence, credit risk, application techniques, trading platforms, security, and anonymity. They also collected Taiwanese Twitter data on cryptocurrencies from 2013 to 2016. Examining both the amounts and sentiments of word-of-mouth expressed in tweets, they found that discussions of monetary systems and currencies were consistently popular. The topic of credit risk also had a high number of tweets, which tended to be negative. On the other hand, the topic of application techniques was less discussed but was more positively skewed. Trading platforms were little discussed in the early period but became more popular after 2015. During this post-2015 period, negative sentiments started to dominate the discussions because of a hacking incident involving bitcoin transactions. The security issue has also increased in popularity since 2015 but has been negatively skewed.

In a similar vein, Matta, Lunesu, and Marchesi (2015) found that the volume of tweets and google trend data correlates with bitcoin prices. Kim et al. (2016) analyzed online datasets (e.g., postings, replies, views, sentiments) drawn from cryptocurrency communities to predict price fluctuations. Their mathematical model revealed that cryptocurrency prices had accuracy gaps of approximately $8 \%$. Predictions were the most precise for bitcoin and least precise for ripple. They concluded that the accuracy of the predicted fluctuations was attributable to the amount of accumulated data based on the degree of communication among community members. They also found that the number of public comments and replies appeared to affect the number of transactions (i.e., buying and selling cryptocurrencies). Thus, differences in communi- 
DRUŠ. ISTRAŽ. ZAGREB GOD. 28 (2019), BR. 3, STR. 435-460

PARK, H. W., LEE, Y.: HOW ARE TWITTER.. ty sizes and activities were found to affect cryptocurrency price fluctuations. Thelwall (2017) attempted to associate the concepts of "network embeddedness" and "connective action" to the financial value of cryptocurrencies using the case of the SteemIt website. He found that SteemIt members strongly recognized the importance of social networks in terms of reciprocal relationships. This finding implies that mutual acknowledgement and networking in cryptocurrency communities may have an effect on the overall performance of individual cryptocurrencies. Last but not least, the work of Lischke and Fabian (2016) and Park and Park (2019) are worth mentioning because they applied social network perspective to cryptocurrency. Lischke and Fabian (2016) examined the first four years of Bitcoin transaction history and revealed the existence of the small world phenomenon in the Bitcoin transaction network over time and across countries. Park and Park (2019) examined whether web traffic and social network metrics reflect financial performances of cryptocurrencies and found positive cross relationships between web traffics, social network attributes, and cryptocurrency performance indicators.

\section{RESEARCH QUESTIONS}

In previous studies on cryptocurrency through social media, it has been revealed that the discourse that various stakeholders generate in the online sphere plays an important role in the economic performance of each cryptocurrency. However, previous studies focused mainly on price fluctuation and its predictors from the consumers' (i.e., coin owners) perspective, lacking the producers' (i.e., developers) perspective. The present study therefore focuses on the online social network activities of cryptocurrency developers and their influence on the market rather than merely focusing on transactions and pricing. It is noteworthy that there is a high level of peer networking between existing dominant cryptocurrencies (e.g., bitcoin, ethereum, ripple) and newly developed ones. Our assumption is that the cryptocurrency market, like conventional stock markets, can be regarded as a multi-layered social structure characterized by networks of actors (Baker, 1984). In the present study, we particularly focus on Twitter activities, where each cryptocurrency is actively channeling news updates to each other and constructing following-follower networks.

Recent advances in social network analysis have provided a number of measures with which to better understand the configurations of connectivity structures among individual components in a social system. This allows researchers to observe patterns among connected cryptocurrencies on social media based on informal partnerships and information exchange. Social media analytics can also help researchers mea- 
DRUŠ. ISTRAŽ. ZAGREB GOD. 28 (2019), BR. 3, STR. $435-460$

PARK, H. W., LEE, Y.: HOW ARE TWITTER... sure the specific attributes of each cryptocurrency in terms of network position. This study poses two research questions:

RQ1: How can social media network and sentiment analysis assist in understanding cryptocurrencies as a communication system? Specifically, what are the Twitter-mediated network properties of cryptocurrencies?

RQ2: How can network embeddedness impact the future performance of cryptocurrencies? Specifically, how are network-based indicators related to the credit scores of cryptocurrencies?

\section{METHOD AND DATA}

Social network analysis (SNA) is "the process of investigating social structures through the use of networks and graph theory" (Otte \& Rousseau, 2002). A social network is composed of nodes and ties (Lee \& Tkach-Kawasaki, 2018; Shapiro et al., 2018). Nodes refers to the individual actors, people, or any things within a networked system and ties (also called links or edges) refers to the relationships or interactions of the nodes (Hanneman \& Riddle, 2005). In this study, we consider twitter accounts of each cryptocurrency as nodes and the relationship between twitter activities such as following, replying, co-tweeting as ties (Xu \& Feng, 2015). Indicators and visualizations based on an SNA are particularly useful for identifying the structural pattern of the online social activities (Otte \& Rousseau, 2002; Park, Jeong, \& Park, 2019; Song, Jung, Kim, \& Park, 2019). Among the various structural properties of social network, we particularly focus on density, which is the total number of ties divided by the total number of possible ties (Hanneman \& Riddle, 2005). In addition to examination of the overall structure and properties of cryptocurrency twitter network, we apply sentiment analysis to investigate what kind of tweet messages are associated with the future performance of cryptocurrencies. Specifically, we employed sentiment analysis that easily produces quantifiable positive or negative coded value of each sentence. Also, additional temporal analysis was performed to explore how changes in the overall sentiment of tweet messages are related to the changes in the market price of cryptocurrency.

The data to be analyzed are from the Twitter text generated by each cryptocurrency account. A total of 74 cryptocurrency accounts is selected as the subject based on the publication by WEISS Rating on January 24, 2018. Tweets were collected on February 20, 2018, via Twitter API embedded in Webometric Analyst 2.0. ${ }^{1}$ A total of 97,326 tweets were collected and analyzed using social network analysis. Figure 1 shows the temporal distribution of the differences between the oldest 
(1) FIGURE 1

Number of days

passed since the first

tweets of each

cryptocurrency

(1) FIGURE 2

Namecoin, the oldest

cryptocurrency tweet collected and most recent tweets collected. We excluded cryptocurrencies' retweets that merely repeated their own tweets. As shown in Figure 2, the oldest tweet came from Namecoin on Saturday April 24, 2011, at 16:23:15; it says, "Namecoin project announced: http://bit.ly/hBIZXc \#namecoin." The Bithares tweet came later, on February 25, 2012. Thus, 2,489 days passed since Namecoin sent the first tweet. Novacoin and RaiBlocks tweeted their first and latest tweets on the same days in 2018, February 2 and 20, respectively.

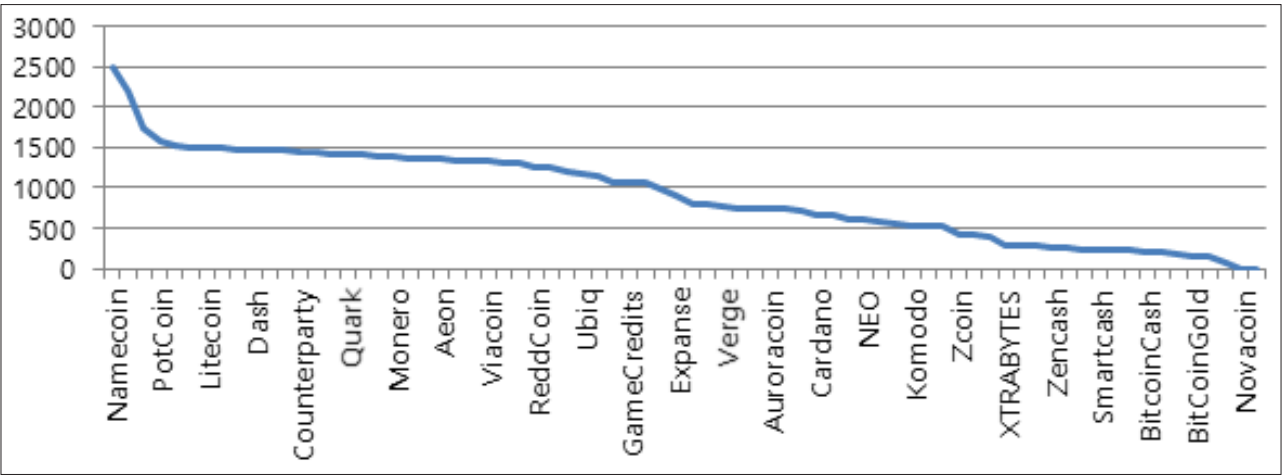

\section{ㄴ. Namecoin 님이 리트윗했습니다}

doublec@doublec.2011년 4월 26일

Namecoin - a distributed \#bitcoin like system for domain names - with a socks 5 adapter to do namecoin lookup http://bit.ly/fnP7ef

(6) 영어 번역하기
Q
† 2
○ 1
9

七] Namecoin 님이 리트윗했습니다

Jon Matonis @jonmatonis·2011년 4월 26일

SSL And The Future Of Authenticity blog.thoughtcrime.org/ssl-and-the-fu...

(6) 영어 번역하기
Q
†】 2
O 1

Namecoin @Namecoin · 2011년 4월 24일

And so it begins. Some of the first Namecoins mined are now available for sale: http://j.mp/eFQEDI

(7) 영어 번역하기
Q
$\uparrow \downarrow 1$
O 1

\section{Namecoin @Namecoin · 2011년 4월 24일}

Namecoin project announced: http://bit.ly/hBIZXc \#namecoin

(7) 영어 번역하기
Q
† 3
O 2
G 


\section{Cross-Sectional Aspects: Followings, followers, and tweets}

Twitter users' ego network structures can be measured using their followings and followers. Since Twitter users with highvolume followings are regarded as active networkers, the number of followers can be used as a proxy measure of an account holder's reputation. As summarized in Table 1, Steem ranked at the top in terms of the number of followings $(13,313)$. The Twitter accounts with the next-highest number of followings were Syscoin $(5,647)$, SaluS $(4,748)$, PotCoin $(3,152)$, and Ark $(2,748)$. The number of followings indicates how strongly a Twitter user seeks to expand its social ties. In contrast to Steem's follower status, it ranked only 22 nd in connections $(85,706)$. Ripple had the most followers $(794,343)$ but was only somewhat ahead of Bitcoin $(780,464)$. These numbers can be used to measure both Ripple's and Bitcoin's influence and the amount of attention they receive. Ethereum $(364,281)$, Dash $(278,928)$, and NEO $(275,115)$ were ranked after them. Whereas followings and/or followers reveal an egocentric visibility and presence regardless of the link direction, the number of tweets represents how a Twitter user intends to share information with its target audience and community members. A close examination

(1) TABLE 1

Twitter rankings of cryptocurrencies in terms of followings, followers, and tweets of the numbers of tweets (excluding the accounts' own retweets) reveals that the top five accounts sent a fairly equal number of messages: the top five were Steem $(3,232)$, Syscoin $(3,229)$, Ripple $(3,222)$, Nxt $(3,216)$, and Bitcoin $(3,205)$.

\begin{tabular}{rllrlrlr}
\hline Rank & Crypto & WEISS & & & & \\
& Rating & Followers & Crypto & Followings & Crypto & Tweets \\
\hline 1 & Ripple & C & 794343 & Steem & 13313 & Steem & 3232 \\
2 & Bitcoin & C+ & 780464 & Syscoin & 5647 & Syscoin & 3229 \\
3 & Ethereum & B & 364281 & SaluS & 4748 & Ripple & 3222 \\
4 & Dash & C+ & 278928 & PotCoin & 3152 & Nxt & 3216 \\
5 & NEO & B- & 275115 & Ark & 2748 & Bitcoin & 3205 \\
6 & Monero & C & 267458 & NEO & 2224 & ReddCoin & 3198 \\
7 & Verge & C & 256851 & Ubiq & 2224 & BlackCoin & 2822 \\
8 & Stellar & C & 209192 & BitShares & 2003 & PotCoin & 2773 \\
9 & Dogecoin & C & 206304 & I/Ocoin & 1865 & DigiByte & 2766 \\
10 & NEM & C+ & 184965 & Expanse & 1822 & Feathercoin & 2546 \\
11 & Ethereum Classic & C & 182326 & Auroracoin & 1572 & Monero & 2504 \\
12 & Lisk & C & 177520 & Stellar & 1548 & Dash & 2459 \\
13 & Qtum & C & 141608 & Counterparty & 1535 & Stellar & 2440 \\
14 & DigiByte & C- & 140789 & Burst & 1366 & NEM & 2286 \\
15 & Stratis & C & 131781 & Zencash & 1224 & Ethereum Classic & 2267 \\
16 & EOS & B & 112803 & Zcoin & 1140 & I/Ocoin & 2067 \\
17 & Cardano & B- & 112096 & Feathercoin & 1123 & Waves & 2010 \\
18 & Electroneum & C- & 107398 & PIVX & 1067 & Verge & 1984 \\
19 & Waves & C & 106901 & Matchpool & 1024 & Expanse & 1920 \\
\hline
\end{tabular}

(Continued) 


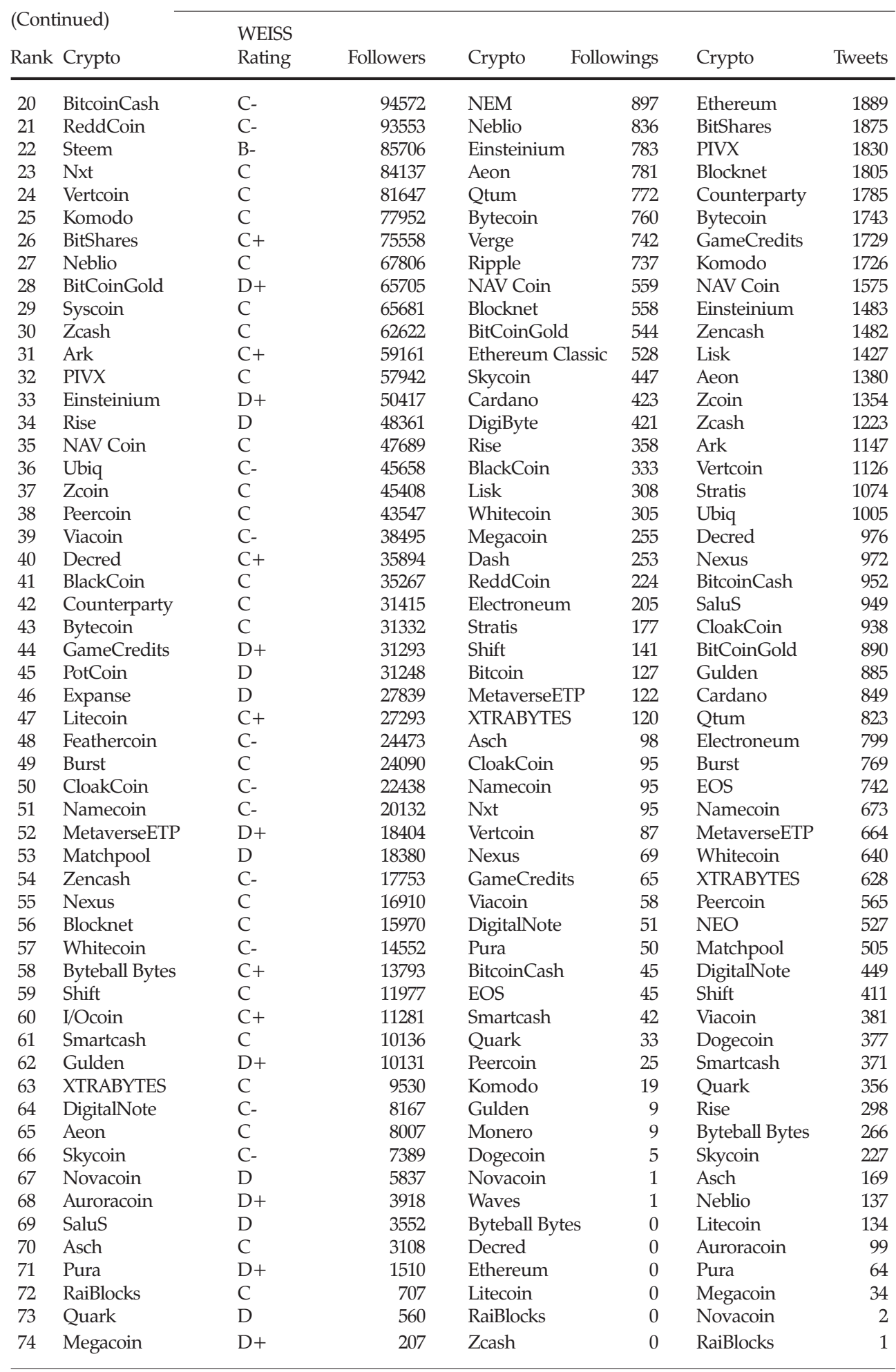


DRUŠ. ISTRAŽ. ZAGREB GOD. 28 (2019), BR. 3, STR. $435-460$

PARK, H. W., LEE, Y.: HOW ARE TWITTER..

$\rightarrow$ TABLE 2

Pearson correlations between ego-centric measures and tweet productivity

\section{○ FIGURE 3}

Network diagram of following-follower relationships
Pearson correlations were conducted for the followings, followers, and tweets. While followers and followings were not at all associated, both numbers had a positive relationship with tweets (see Table 2). Tweets and followers had a higher correlation coefficient value than did tweets and followings, suggesting that productivity might facilitate the achievement of a higher status.

\begin{tabular}{lll}
\hline Measures & Followings & Followers \\
\hline Tweets & $0.347^{* * *}$ & $0.475^{* * *}$ \\
\hline
\end{tabular}

$\mathrm{N}=74 ;{ }^{* *} p<0.001$

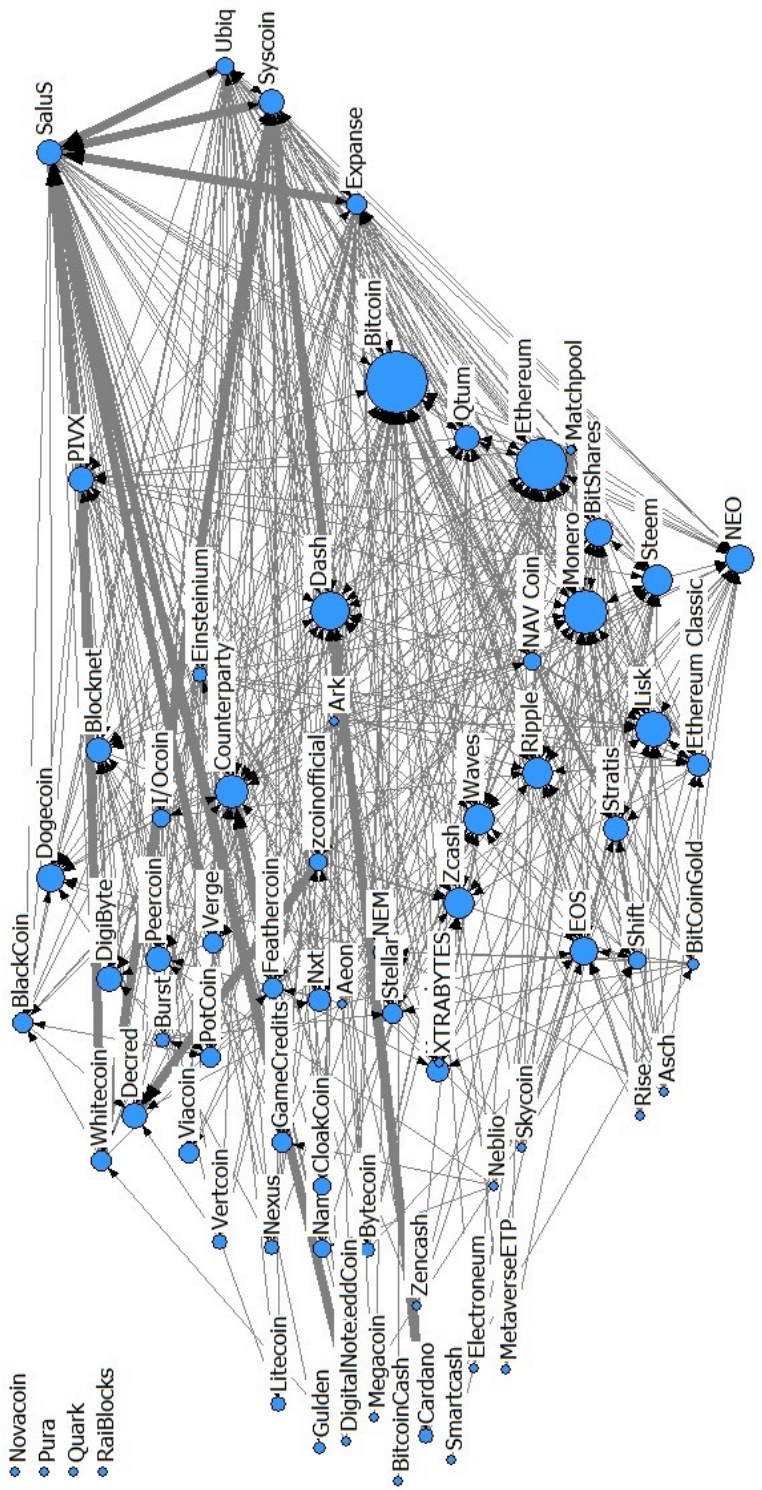


DRUŠ. ISTRAŽ. ZAGREB GOD. 28 (2019), BR. 3, STR. 435-460

PARK, H. W. LEE, Y.: HOW ARE TWITTER...

Э FIGURE 4 Network diagram of reply-mention relationships
The network diagram reveals that during this period subscription-based networks had a relationship structure different from that of broadcasting-based networks. The followingfollower network was dominated by lesser-known cryptocurrencies, particularly in outdegree centralities, whereas its indegree structure was dominated by celebrity currencies. Figure 3 visualizes the following-follower cryptocurrency Twitter network using a principal components layout algorithm. Among the 74 Twitter users, SaluS and Syscoin had the highest outdegree centralities (both have normalized values of 0.60 ), with Ubiq (0.53), Expanse (0.48), and Matchpool (0.38) following. The top five currencies for indegree centrality were Bitcoin (0.52), Ethereum (0.42), Monero (0.33), Dash (0.29), and Lisk (0.26).

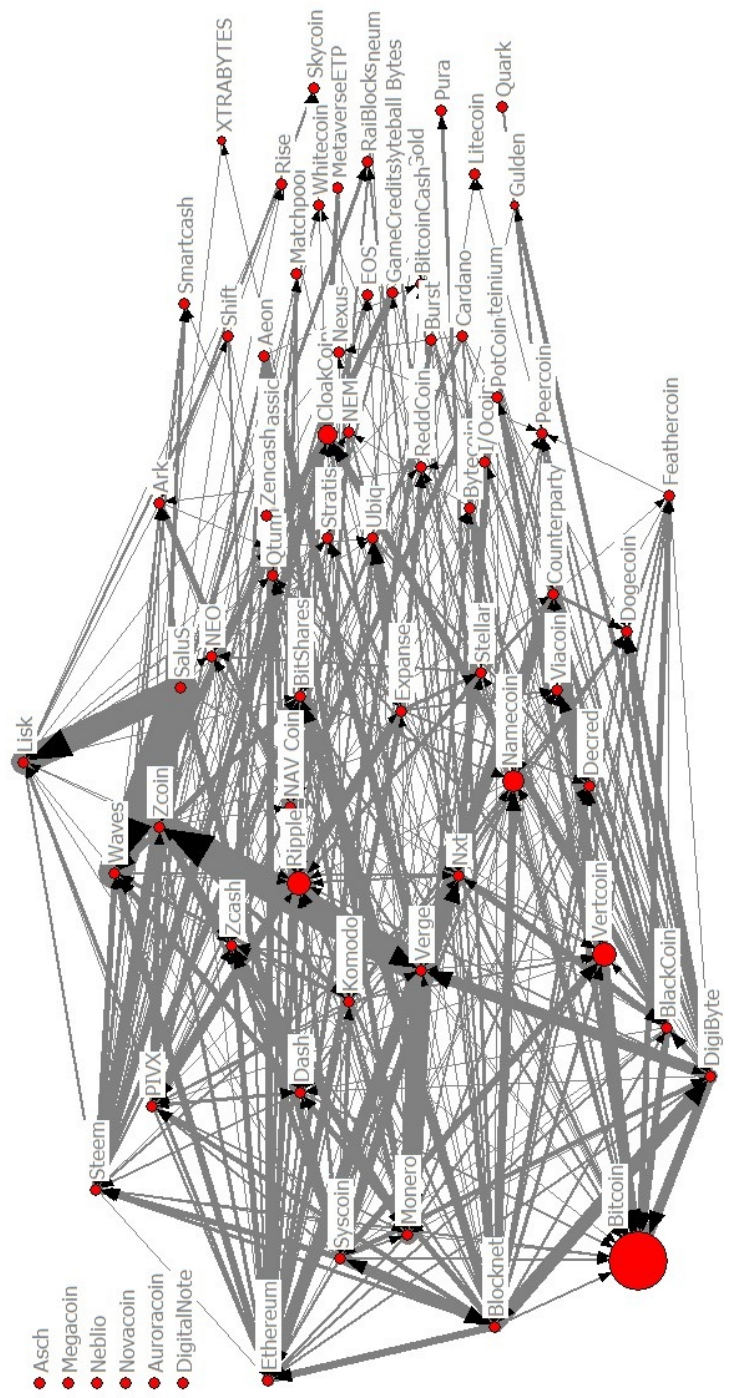


DRUŠ. ISTRAŽ. ZAGREB GOD. 28 (2019), BR. 3, STR. $435-460$

PARK, H. W., LEE, Y.: HOW ARE TWITTER..
To examine the resource-exchange tweet network, we created a concrete message-circulating map by parsing replies and mentions from the collected tweet data. As visualized in Figure 4, Ethereum (1.75) was the most replied/mentioned account. Bitcoin (1.34), Steem (1.26), and Waves (1.08) all had indegree centrality values above 1 , while Monero (0.96) was ranked fifth. Similarly to the following-follower network, minor currencies made the strongest efforts to send information to promote their social media profile and achieve a better online presence. The currencies with the most outdegree centralities were Blocknet (1.81), SaluS (1.67), Verge (1.29), Syscoin (1.22), DigiByte (1.01), and Zcoin (0.93). On the other hand, the outdegree centralities of the currencies with the top five indegree centralities held peripheral positions: Ethereum (0.04), Bitcoin (0.00), Steem (0.12), Waves (0.34), and Monero (0.30).

We created a detailed communication interactions map using digital trace data. Figure 5 represents a co-tweeted network cartography in which two cryptocurrency Twitter accounts receive messages simultaneously from a third account. Contrary to both the following-follower and reply-mention networks, the co-tweeted network does not contain a directed message (i.e., the number of tweets sent and received). For example, "@monerocurrency@ethereumprojct awesome" is a co-tweet between Monero and Ethereum. Thus, the lines between these two currencies have a thickness proportional to the number of tweets sent to both of them at the same time. Hence, the co-tweeted network analysis on cryptocurrencies offers a new perspective and provides insights that were not possible using the previous following-follower and replymention techniques. The number of isolates in the co-tweeted network (as illustrated in Figure 5) is 22, compared to four and six in the other two networks. The top 10 currencies in terms of degree centrality are Monero (1.04), Ethereum (0.93), Dogecoin (0.87), Dash (0.84), Vertcoin (0.82), Bitcoin (0.76), Zcash (0.68), CloakCoin (0.57), Steem (0.57), and Stellar (0.57). The 10 currencies with the highest betweenness are Ethereum (0.09), Monero (0.07), Bitcoin (0.05), Dash (0.04), Dogecoin (0.04), Ripple (0.04), Lisk (0.03), DigiByte (0.03), Stellar (0.03), and Vertcoin (0.03).

As summarized in Table 3, the results indicate that the reply-mention network had the densest structure (density = 0.251 ). Some $25.1 \%$ of the cryptocurrencies are mentioned and/or replied to. With 1,358 ties overall, the cryptocurrencies had approximately 19 Twitter conversation partners. Given that the following-follower network represents a ritual relationship, it is interesting to find that it is the least dense. On the other hand, both the reply-mention and co-tweeted networks form a fairly flat community, as the accounts specifically refer to and tag their conversation partners. 


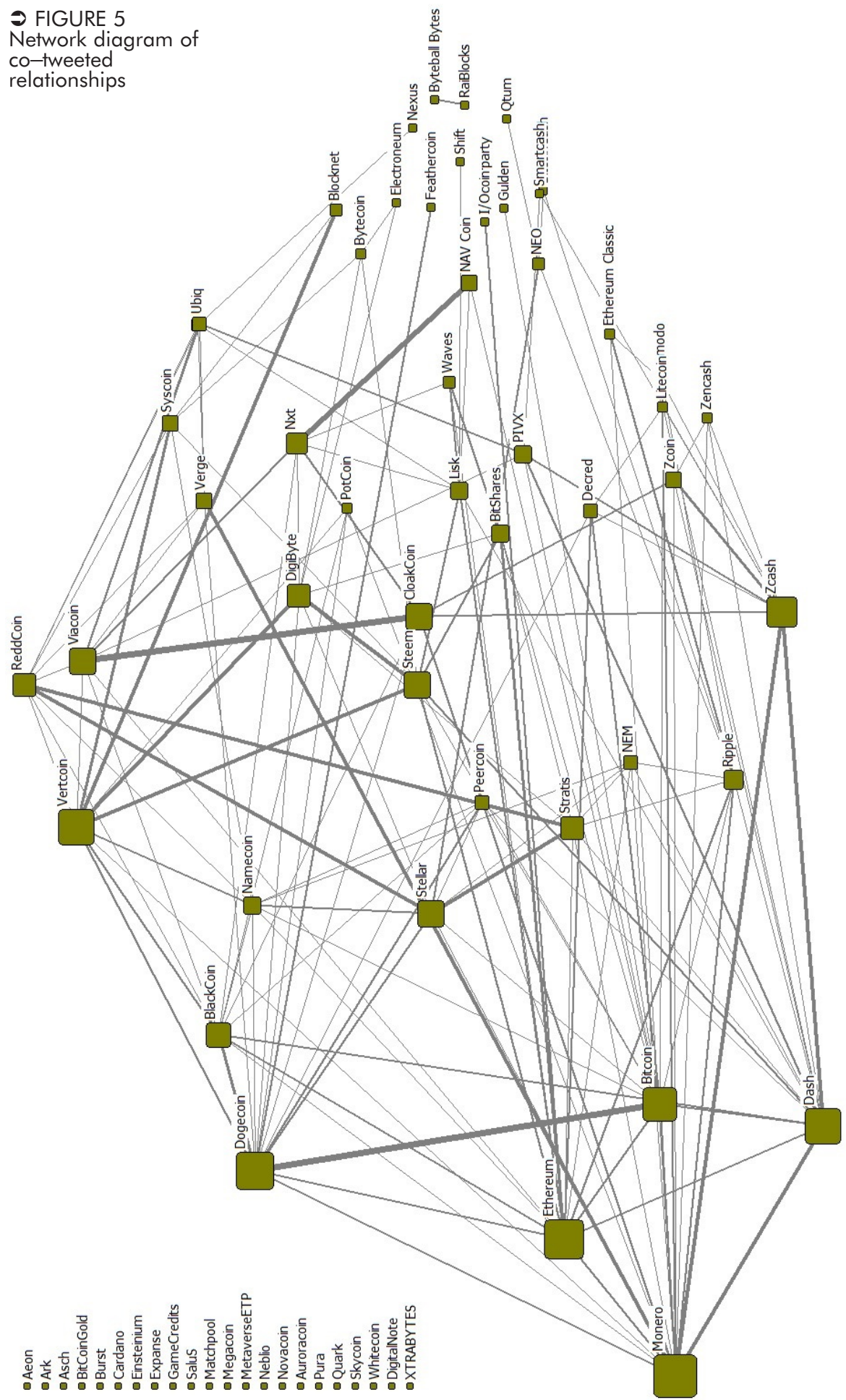


$\rightarrow$ TABLE 3

Density and associated statistics for the three cryptocurrency networks ( $\mathrm{N}=74)$
(1) TABLE 4

Multiple network measures $^{2}(\mathrm{~N}=74)$
Network types

$$
\text { Following- }
$$
follower

$$
\begin{aligned}
& \text { Reply- } \\
& \text { mention }
\end{aligned}
$$

Co-tweet

\begin{tabular}{lrrr}
\hline Density & 0.102 & 0.251 & 0.216 \\
Total number of ties & 551 & 1.358 & 1.168 \\
Standard deviation & 0.309 & 1.511 & 1.144 \\
Average value of ties & 7.446 & 18.351 & 15.784 \\
\hline
\end{tabular}

$\mathrm{N}=74$

Let us further examine the additional statistics in order to uncover the overall picture of the three networks (Table 4). This set of network measures was computed using a multiple structure option in UCInet. The indeg H-Index is the largest in the following-follower network because the number of nodes with at least ' $\mathrm{H}$ ' ties is the highest in the network. As alluded

\begin{tabular}{|c|c|c|c|c|}
\hline Index & Definitions & $\begin{array}{l}\text { Following- } \\
\text { follower }\end{array}$ & $\begin{array}{l}\text { Reply- } \\
\text { mention }\end{array}$ & Co-tweet \\
\hline Indeg H-Index & $\begin{array}{l}\text { Largest number } \mathrm{x} \text { such that there are } \\
\mathrm{x} \text { vertices of degree at least } \mathrm{x} \text { in the } \\
\text { underlying graph }\end{array}$ & 13.000 & 11.000 & 10.000 \\
\hline Compactness & Mean of all the reciprocal distances & 0.239 & 0.305 & 0.220 \\
\hline Closure & $\begin{array}{l}\text { Number of non-vacuous transitive triples } \\
\text { divided by number of paths of length } 2\end{array}$ & 0.513 & 0.337 & 0.345 \\
\hline Avg Distance & $\begin{array}{l}\text { Average geodesic distance amongst } \\
\text { reachable pairs }\end{array}$ & 2.318 & 2.668 & 2.406 \\
\hline SD Distance & $\begin{array}{l}\text { Standard deviation of the geodesic } \\
\text { distances amongst reachable pairs }\end{array}$ & 1.029 & 1.112 & 0.844 \\
\hline Wiener Index & Average shortest path distance & 5587.000 & 9627.000 & 5900.000 \\
\hline Diameter & Length of the longest geodesic distance & 7.000 & 8.000 & 5.000 \\
\hline Deg Centralization & $\begin{array}{l}\text { Sum of the squares of the proportion } \\
\text { of the total centrality held by each node }\end{array}$ & 0.503 & 0.307 & 0.206 \\
\hline Nulls & Number of cells with null values & 0.812 & 0.850 & 0.940 \\
\hline Dependency Sum & $\begin{array}{l}\text { Sum of the betweenness proportions } \\
\text { of } Y \text { for all pairs which involve node } X\end{array}$ & 3177.000 & 6019.000 & 3448.000 \\
\hline
\end{tabular}
to earlier, the following-follower network has the least uneven structure.

To calculate the correlations between the equivalent cells of the three Twitter networks, we employed the quadratic assignment procedure (QAP) in UCINet. While the following-follower network structure was correlated with the reply-mention network $(r=0.172, p<0.001)$, it had no statistically significant association with the co-tweet network. How- 
DRUŠ. ISTRAŽ. ZAGREB GOD. 28 (2019), BR. 3, STR. 435-460

PARK, H. W., LEE, Y.: HOW ARE TWITTER..

P TABLE 5

Pearson correlations between network measures and credit scores ever, the latter two networks were positively correlated with each other $(r=0.112, p<0.001)$. These findings indicate that having a direct friendship (following) and/or audience (follower) can lead to actual communication.

Credit scores were correlated with several network measures for the 74 cryptocurrencies (see Table 4). The Pearson correlation between Weiss ratings and indegree centralities was highest in the following-follower network $(r=0.492, p<0.001)$, implying that the more credible a cryptocurrency is judged to be, the better connected it is. The strength of the correlation between credit ratings and indegree centralities was somewhat lower in the reply-mention network than in the following-follower network $(r=0.417, p<0.001)$. The betweenness centralities in the following-follower network had no correlation with ratings, but the betweenness values in the replymention network had a positive relationship $(r=0.228, p<0.05)$. In the co-tweet network, the correlation between degree centralities and ratings dropped to $0.330(p<0.001)$, indicating that the (in)direct connectivity pattern between cryptocurrencies is an important determinant of their financial success. Additionally, the number of followers $(r=0.367, p<0.001)$ and tweets (excluding their own retweets; $r=0.220, p<0.05$ ) also had significant associations with ratings.

\begin{tabular}{llc}
\hline Network types & Measures & $\begin{array}{c}r \text { values with } \\
\text { Weiss ratings }\end{array}$ \\
\hline Following-follower & Indegree centralities & $0.492^{* * *}$ \\
Reply-mention & Indegree centralities & $0.417^{* * *}$ \\
& Betweenness & $0.228^{*}$ \\
Co-tweet & Degree centralities & $0.330^{* * *}$ \\
General & Number of followers & $0.367^{* * *}$ \\
& Number of tweets & $0.220^{*}$ \\
\hline
\end{tabular}

$\mathrm{N}=74 ;{ }^{* *} p<0.001,{ }^{*} p<0.05$

\section{Longitudinal Aspects: Sentiment Stream}

Considering the exploratory nature of the analysis, we decided to use data visualization technique rather than traditional time-series statistics. Data visualization has moved from the engineering and technical research community into widespread use, driven by the increased use of various tools with open and/ or affordable prices. Among the many tools, this study presents examples of using Tableau to perform both visualization and statistical analysis. According to Murray (2013), Tableau has been rapidly growing in popularity in research and development, and in many other areas. One of the most powerful techniques of Tableau is VizQ (Visual Query Language), which helps skip complex steps for analysis and creates visual analytics of data right away, just by using drag and drop 
DRUŠ. ISTRAŽ. ZAGREB GOD. 28 (2019), BR. 3, STR. $435-460$

PARK, H. W., LEE, Y.: HOW ARE TWITTER...

TABLE 6

Overall distribution of positive and negative sentiments expressed in tweets

- TABLE 7

Descriptive statistics of positive and negative sentiments functions. That query language translates the user's action into a database query represented in a variety of types of graphs.

To produce visualization data, all the tweets posted by each cryptocurrency account were harvested using Webometric Analyst 2.0 (Thelwall, 2014). A total of 89,326 tweets have been collected from the same data source. The present study focuses on the sentiment of each tweet message, which may have a potential impact on the public regarding a future buy-or-sell decision. For succinct expression of data and its interpretation, sentiment represented in the tweets was categorized as a 5-point Likert scale via SentiStrength software that is often used together with Webometric Analyst (Thelwall, Buckley, \& Paltoglou, 2012). The sentiment of each tweet is coded from 1 (least positive) to 5 (strongly positive) or -1 (least negative) to -5 (strongly negative). Next, descriptive statistics and visualization have been done using the Tableau.

\begin{tabular}{lrrcrr}
\hline Positive & Frequency & Percent & Negative & Frequency & Percent \\
\hline 1 & 60,543 & 68.00 & -1 & 73,692 & 82.70 \\
2 & 20,662 & 23.20 & -2 & 13,383 & 15.00 \\
3 & 7,165 & 8.00 & -3 & 1,565 & 1.80 \\
4 & 6,68 & 0.80 & -4 & 395 & 0.40 \\
5 & 20 & 0.00 & -5 & 23 & 0.00 \\
Total & 89,058 & 100.00 & Total & 89,058 & 100.00
\end{tabular}

There are more negative emotions expressed than friendly ones in terms of the weakest intensity of emotion. In Table $6,82.7$ percent of the negative tweets are at the lowest level (-1) while 68.0 percent had the lowest level of positive tweets $(+1)$. In the +2 and +3 sections, 23.2 percent and 8.0 percent occurred, respectively. Both are higher than their negative scores. Interestingly, the share of the strongest emotions is extremely low on both positive and negative parts of the scale. The overall mood in the tweet message is friendly rather than hostile as the average of positive tweets was 1.42, slightly higher than the -1.2 expressing the negative message. The means, standard deviations, variances, and kurtosis are listed in Table 7.

\begin{tabular}{lrr}
\hline & Positive & Negative \\
\hline N & 89058 & 89058 \\
Mean & 1.42 & -1.2 \\
S.D. & 0.672 & 0.474 \\
Variance & 0.452 & 0.225 \\
Skewness value & 1.504 & -2.671 \\
Skewness standard deviation & 0.008 & 0.008 \\
Kurtosis & 1.534 & 8.37 \\
Kurtosis standard deviation & 0.016 & 0.016 \\
\hline
\end{tabular}


DRUŠ. ISTRAŽ. ZAGREB GOD. 28 (2019), BR. 3, STR. 435-460

PARK, H. W., LEE, Y.: HOW ARE TWITTER.

\section{$\ni$ FIGURE 6}

Temporal analysis of sentiments of cryptocurrency tweets
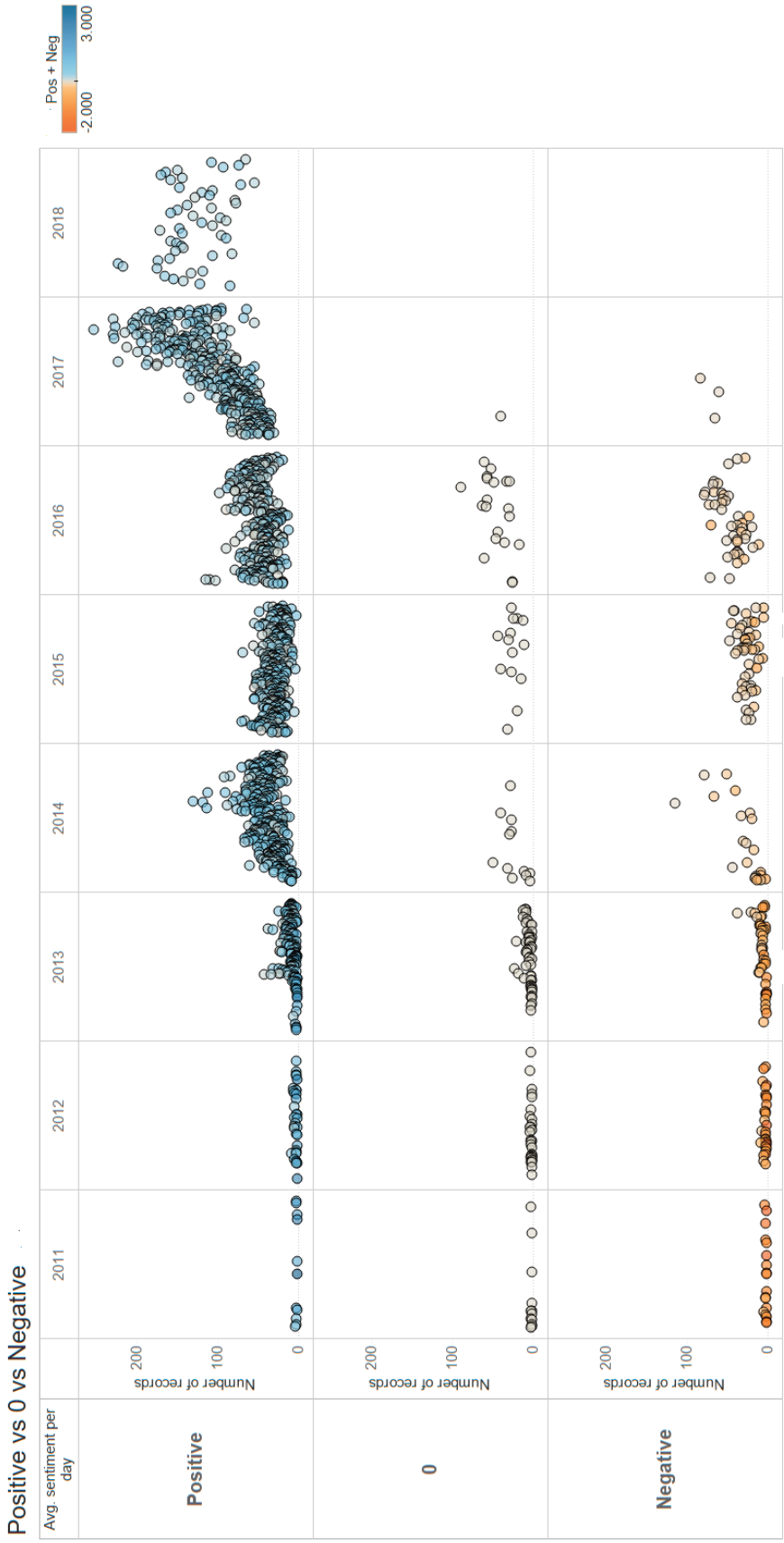

The results are more interesting when compared year by year. Both 'year' and 'day' were placed in columns. The reason was to show the daily trend of decreasing negative values and zero values within a year, as well as the increasing positive values in a more visible way. Zero is the sum of the values for 
DRUŠ. ISTRAŽ. ZAGREB GOD. 28 (2019), BR. 3, STR. $435-460$

PARK, H. W., LEE, Y.: HOW ARE TWITTER.. positive and negative messages occurring daily. In 2017, when the price of most cryptocurrency skyrocketed, nearly all the messages of negative emotion disappeared, while the positive messages of support and encouragement increased rapidly. It is worth mentioning that there was one zero in 2017. The sum of positive and negative values was zero for just one day on February 25. A total of 40 messages were produced on this day. Then, the price of cryptocurrency dropped from its peak as it moved to 2018. The price changes also affected the mood on Twitter. The positive tweets for 2018 were drastically reduced.

\section{DISCUSSION AND CONCLUSION}

Amid the rapid increase in the popularity of cryptocurrencies in recent years, few studies have conducted social media analytics to examine Twitter activities. Moreover, the relationships between cryptocurrencies' market status and their social connections have not yet been examined. The findings of the current study revealed that analyzing the social interaction surrounding cryptocurrencies can help understand the dynamics and complexity of the cryptocurrency market. Contributions and limitations are discussed as below.

First, this study applied social network analysis to the Twitter accounts of cryptocurrencies. Findings appear to support our argument that measuring social media presence of a cryptocurrency may allow its more accurate evaluation. We investigated the similarities/differences between three types of friendship on Twitter as well as the association strengths between cryptocurrencies' network-based positions and financial evaluation scores. The findings revealed substantial differences in structure among the friendship networks. The actual tweet network was more than twice as dense and had twice the average value of social ties than the ritual relationship network had, and the reply-mention network was greater than either of the others. More importantly, the indegree centralities of cryptocurrencies in the three networks had a positive association with their financial performance. Additionally, as the tweet volume increased, cryptocurrencies were more likely to expand their friends in both inward and outward directions. For this phenomenon, organizational theory explains the selection of strategic partners on the network to reduce uncertainty (Pfeffer \& Salancik, 1978; Burt, 1983; Gargiulo, 1993). Especially in emerging markets like cryptocurrency, companies tend to broaden their networks to learn new practices and technologies from their peers (Kogut, 1988; Powell, Koput, \& Smith-Doerr, 1996). When replying-mentioning activity on Twitter is a part of broadening or reinforcing network partners, our analysis revealed that existing dominant cryptocurrencies attempt to strengthen their network to reduce market uncertainty, and new entrants try to establish new networks 
DRUŠ. ISTRAŽ. ZAGREB GOD. 28 (2019), BR. 3, STR. 435-460

PARK, H. W., LEE, Y.: HOW ARE TWITTER..

\section{NOTES}

or expand their networks continuously to reduce firm-specific uncertainty. These findings are consistent with previous organizational studies that explain how interorganizational networks are changed by market uncertainty and forms of relationships (e.g., Beckman, Haunschild, \& Phillips, 2004; Komorowski, Huu, \& Deligiannis, 2018). However, the results have several limitations in which there were constraints on collecting data of a scale large enough to acquire statistical rigor, and therefore we relied only on social network metrics and simple correlation analysis. Future empirical study may enrich our findings with more generalizable evidence.

Second, considering the entire cryptocurrency market as a complex social system, our results open a new research stream of developing a method to estimate the returns and volatility of cryptocurrency prices during bear and bull markets. Although the analysis is exploratory, we find a reasonable similarity in patterns between upbeat sentiments on tweets and a bullish market trend. This is consistent with the previous research on the effect of user sentiment on SockTwits on the stock returns (Deng, Huang, Sinha, \& Zhao, 2018). However, it is too soon to conclude whether positive sentiments or negative sentiments predict cryptocurrency market prices. Further research is required to validate this finding with a wide time-series analysis. Nonetheless it implies we need multidimensional measurement on evaluating cryptocurrency combining traditional sources (e.g. official institute, news) and new sources (e.g. social media). In future research, various attempts should be made to analyze the cryptocurrency phenomena and evaluate future values with scientific methodologies. As a small number of cryptocurrencies dominate the market in terms of network power, an attempt to develop an overall cryptocurrency market index incorporating network analysis is one promising research area (e.g., Chi, Liu, \& Lau, 2010). Weiss Ratings is currently the only indicator available for evaluating individual cryptocurrencies. Considering the increase in transaction volume and public attention on cryptocurrency, more reliable indicators should be developed by various institutions and academia. In addition, a new comprehensive index should be constructed to reflect the influence, status, and public interest in cryptocurrency in social media.

* The authors thank Seung-Il Kang for helping visualize sentiment analyses via Tableau software. Another thanks go to Pieter Stek and Bon-Woo Koo for their assistance while conducting current research project.

${ }^{1}$ For details on the procedures used, see http://lexiurl.wlv.ac.uk/ searcher/twitterConversationNetworks.html. 
${ }^{2}$ For the detailed definitions, refer to the followings sources, Hanneman \& Riddle, 2005; Park, Yoon, \& Leydesdorff, 2016; van Liere, 2004.

Baker, W. E. (1984). The social structure of a national securities market. American Journal of Sociology, 89(4), 775-811. https://doi.org/10.1086/ 227944

Beckman, C. M., Haunschild, P. R., \& Phillips, D. J. (2004). Friends or strangers? Firm-specific uncertainty, market uncertainty, and network partner selection. Organization Science, 15(3), 259-275. https://doi.org/ 10.1287/orsc. 1040.0065

Blazquez, D., \& Domenech, J. (2017). Big Data sources and methods for social and economic analyses. Technological Forecasting and Social Change, 130, 99-113. https://doi.org/10.1016/j.techfore.2017.07.027

Brandão, A., Mamede, H. S., \& Gonçalves, R. (2018). Systematic review of the literature, research on blockchain technology as support to the trust model proposed applied to smart places. In Á. Rocha, H. Adeli, L. P. Reis, \& S. Costanzo (Eds.), Trends and advances in information systems and technologies (pp. 1163-1174). WorldCIST'18 2018. Advances in Intelligent Systems and Computing, vol 745. Springer, Cham. https://doi.org/10.1007/978-3-319-77703-0_113

Brito, J., Shadab, H. B., \& Castillo, A. (2014). Bitcoin financial regulation: Securities, derivatives, prediction markets, and gambling. Columbia Science and Technology Law Review, 16, 144-221. https://doi.org/10. 2139/ssrn.2423461

Burt, R. S. (1983). Corporate profits and cooptation: Networks of market constraints and directorate ties in the American economy. New York: Academic Press.

Buterin, V. (2014). A next-generation smart contract and decentralized application platform. Ethereum, 1-36. http://buyxpr.com/build/pdfs/ EthereumWhitePaper.pdf

Chi, K. T., Liu, J., \& Lau, F. C. M. (2010). A network perspective of the stock market. Journal of Empirical Finance, 17(4), 659-667. https://doi. org/10.1016/j.jempfin.2010.04.008

Chohan, U. W. (2017). Cryptocurrencies: A brief thematic review. Available at Social Science Research Network (SSRN). Date accessed 28 august 2017. https://doi.org/10.2139/ssrn.3024330

Deng, S., Huang, Z. J., Sinha, A. P., \& Zhao, H. (2018). The interaction between microblog sentiment and stock return: An empirical examination. MIS Quarterly, 42(3), 895-918. https://doi.org/10.25300/MISQ/ 2018/14268

Friedlmaier, M., Tumasjan, A., \& Welpe, I. M. (2017). Disrupting industries with blockchain: The industry, venture capital funding, and regional distribution of blockchain ventures. Proceedings of the 51st Hawaii International Conference on System Sciences | 2018. https://doi.org/ 10.24251/HICSS.2018.445

Garcia, D., Tessone, C. J., Mavrodiev, P., \& Perony, N. (2014). The digital traces of bubbles: Feedback cycles between socio-economic signals in the Bitcoin economy. Journal of the Royal Society Interface, 11(99), 20140623. https://doi.org/10.1098/rsif.2014.0623 
DRUŠ. ISTRAŽ. ZAGREB GOD. 28 (2019), BR. 3, STR. 435-460

PARK, H. W., LEE, Y.: HOW ARE TWITTER..
Gargiulo, M. (1993). Two-step leverage: Managing constraint in organizational politics. Administrative Science Quarterly, 38(1), 1-19. https://doi. org/10.2307/2393252

Goldman Sachs (2018). Top of mind: Is bitcoin a (bursting) bubble? Issue 64 . Hanneman, R. A., \& Riddle, M. (2005). Introduction to social network methods. CA: University of California, Riverside. Available at https:// faculty.ucr.edu/ hanneman/nettext/ (Retrieved July 1, 2013)

Hayes, A. S. (2017). Cryptocurrency value formation: An empirical study leading to a cost of production model for valuing bitcoin. Telematics and Informatics, 34(7), 1308-1321. https://doi.org/10.1016/j.tele. 2016.05.005

Henry, C. S., Huynh K. P., \& Nicholls, G. (2017). Bitcoin awareness and usage in Canada. Bank of Canada.

Hileman, G., \& Rauchs, M. (2017). 2017 global cryptocurrency benchmarking study (April 6, 2017). Available at SSRN. https://doi.org/10. 2139/ssrn.2965436

Hyvärinen, H., Risius, M. \& Friis, G. (2017). A blockchain-based approach towards overcoming financial fraud in public sector services. Business E Information Systems Engineering, 59(6), 441-456. https://doi. org/10.1007/s12599-017-0502-4

Kim, Y. B., Kim, J. G., Kim, W., Im, J. H., Kim, T. H., Kang, S. J., et al. (2016). Predicting fluctuations in cryptocurrency transactions based on user comments and replies. PLOS ONE 11(8), e0161197. https://doi. org/10.1371/journal.pone.0161197

Kogut, B. (1988). Joint ventures: Theoretical and empirical perspectives. Strategic Management Journal, 9(4), 319-332. https://doi.org/10. 1002/smj.4250090403

Komorowski, M., Huu, T. D., \& Deligiannis, N. (2018). Twitter data analysis for studying communities of practice in the media industry. Telematics and Informatics, 35(1), 195-212. https://doi.org/10.1016/j.tele.2017.11.001

Lee, J., \& Tkach-Kawasaki, L. (2018). The relationship between information-sharing and resource-sharing networks in environmental policy governance: Focusing on in Germany and Japan. Journal of Contemporary Eastern Asia, 17(2), 176-199. https://doi.org/10.17477/ jcea.2018.17.2.176

Lischke, M., \& Fabian, B. (2016). Analyzing the Bitcoin network: The first four years. Future Internet, 8(1), 7. https://doi.org/10.3390/fi8010007

Lu, H.-K., Yang, L.-W., Lin, P.-C., Yang, T.-H., \& Chen, A. N. (2017). A study on adoption of bitcoin in Taiwan: Using big data analysis of social media. Proceedings of the 3rd International Conference on Communication and Information Processing (pp. 32-38). Toky, Japan. https://doi.org/10.1145/3162957.3163046

Marsal-Llacuna, M. L. (2017). Future living framework: Is blockchain the next enabling network? Technological Forecasting and Social Change, 128, 226-234. https://doi.org/10.1016/j.techfore.2017.12.005

Matta, M., Lunesu, I., \& Marchesi, M. (2015, June). Bitcoin spread prediction using social and web search media. In UMAP Workshops.

Murray, D. G. (2013). Tableau your data!: Fast and easy visual analysis with tableau software. 
DRUŠ. ISTRAŽ. ZAGREB GOD. 28 (2019), BR. 3, STR. $435-460$

PARK, H. W., LEE, Y.: HOW ARE TWITTER..
Nakamoto, S. (2008). Bitcoin: A peer-to-peer electronic cash system. Available at https://www.bitcoin.org (1st May 2018)

Narayanan, A., Bonneau, J., Felten, E., Miller, A., \& Goldfeder, S. (2016). Bitcoin and cryptocurrency technologies: A comprehensive introduction. Princeton: Princeton University Press.

Otte, E., \& Rousseau, R. (2002). Social network analysis: A powerful strategy, also for the information sciences. Journal of Information Science, 28(6), 441-453. https://doi.org/10.1177/016555150202800601

Park, H. W., Yoon, J. W., \& Leydesdorff, L. (2016). The normalization of co-authorship networks in the bibliometric evaluation: The government stimulation programs of China and Korea. Scientometrics, 109(2), 1017-1036. https://doi.org/10.1007/s11192-016-1978-2

Park, S. J., Jeong, D. H., \& Park, H. W. (2019). Analytical framework for evaluating digital diplomacy using network analysis and topic modeling: Comparing South Korea and Japan. Information Processing and Management, 56(4), 1468-1483. https://doi.org/10.1016/j.ipm.2018.10.021

Park, S., \& Park, H. W. (2019 Online First). Diffusion of cryptocurrencies: Web traffic and social network attributes as indicators of cryptocurrency performance. Quality $\mathcal{E}$ Quantity. https://doi.org/10 .1007/s11135-019-00840-6

Pfeffer, J., \& Salancik, G. (1978). The external control of organizations: A resource dependence perspective. New York: Harper and Row.

Powell, W. W., Koput, K. W., \& Smith-Doerr, L. (1996). Interorganizational collaboration and the locus of innovation: Networks of learning in biotechnology. Administrative Science Quarterly, 411(1), 116-145. https://doi. org $/ 10.2307 / 2393988$

Redek, T., \& Godnov, U. (2018). Twitter as a political tool in EU countries during the economic crisis: A comparative text-mining analysis. Društvena istraživanja, 27(4), 691-711. https://doi.org/10.5559/di.27.4.06

Shapiro, M. A., Brunner, E., \& Li, H. (2018). Strength in numbers and voice: An assessment of the networking capacity of Chinese ENGOs. Journal of Contemporary Eastern Asia, 17(2), 147-175. https://doi.org/10. 17477/jcea.2018.17.2.147

Shiller, R. J. (2000). Irrational exuberance. Princeton: Princeton University Press.

Song, M. S., Jung, K. J., Kim, J. Y., \& Park, H. W. (2019). Risk communication on social media during the Sewol ferry disaster. Journal of Contemporary Eastern Asia, 18(1), 189-216. https://doi.org/10.17477/jcea. 2019.18.1.189

Swan, M. (2015). Blockchain: Blueprint for a new economy. O'Reilly Media, Inc.

Thelwall, M. (2014). Big data and social web research methods. Available at http://www.scit.wlv.ac.uk/čcm1993/papers/IntroductionToWebometrics AndSocialWebAnalysis.pdf.

Thelwall, M., Buckley, K., \& Paltoglou, G. (2012). Sentiment strength detection for the social Web. Journal of the American Society for Information Science and Technology, 63(1), 163-173. https://doi.org/10.1002/asi.21662 
DRUŠ. ISTRAŽ. ZAGREB GOD. 28 (2019), BR. 3, STR. 435-460

PARK, H. W., LEE, Y.: HOW ARE TWITTER..
Thelwall, M. (2017 Online First). Can social news websites pay for content and curation? The SteemIt cryptocurrency model. Journal of Information Science, 1-24. https://doi.org/10.1177/0165551517748290

van Liere, D. (2004). Interpretation of UCINET output. Essex Summer School Version 1.0.

Veloff, M. (2018). Why the Weiss ratings are flawed: A case study. Available at https://www.dashforcenews.com/weiss-ratings-flawed-case-study/

Weiss (2018a). Weiss cryptocurrency ratings explained. Available at https:// weisscryptocurrencyratings.com/ratings/the-weiss-cryptocurrency ratings-explained-15.

Weiss (2018b). Why bitcoin is not an A. Available at https://weisscryp tocurrencyratings.com/btc/why-bitcoin-is-not-an-a-118

Wörner, D., Von Bomhard, T., Schreier, Y. P., \& Bilgeri, D. (2016). The Bitcoin ecosystem: Disruption beyond financial services? Proceedings of the Twenty-Fourth European Conference on Information Systems (ECIS), İstanbul, Turkey.

Xu, W. W., \& Feng, M. (2015). Networked creativity on the CensoredWeb 2.0: Chinese users' Twitter-based activities on the issue of Internet censorship. Journal of Contemporary Eastern Asia, 14(1), 23-43. https://doi.org/10.17477/jcea.2015.14.1.023

Yli-Huumo, J., Ko, D., Choi, S., Park, S., \& Smolander, K. (2016) Where is current research on blockchain technology? - A systematic review. PLoS ONE, 11(10), e0163477. https://doi.org/10.1371/journal.pone.0163477

\section{Kako su aktivnosti na Twitteru povezane s ponašanjem najpoznatijih kriptovaluta? Dokazi iz analize društvenih mreža i analize sentimenta}

Han Woo PARK

Sveučilište Yeungnam, Gyeong-san, Republika Koreja

Youngioo LEE

Nacionalna agencija za informatizaciju, Daegu, Republika Koreja

Kriptovalute su prigrlile Twitter kao glavni kanal komunikacije kojim prenose novosti i grade odnose s (potencijalnim) ulagačima i kupcima. Služeći se analizom društvenih mreža i analizom sentimenta, rad istražuje Twitterom posredovano komunikacijsko ponašanje kriptovaluta proučavanjem učestalosti tvitova te njihovih struktura: following-follower, reply-mention i co-tweet. Ocjene tržišta često znatno utječu i na proizvođače (ti. programere) i na potrošače (ti. vlasnike kriptovaluta). Stoga ovo istraživanje utvrđuje postoji li povezanost između Twitterovih mreža kriptovaluta i njihovih kreditnih ocjena. Podaci su prikupljeni na Twitterovim stranicama niza najpoznatijih kriptovaluta. Rezultati pokazuju da su reply-mention mreže imale najgušću 
DRUŠ. ISTRAŽ. ZAGREB GOD. 28 (2019), BR. 3, STR. $435-460$

PARK, H. W., LEE, Y.: HOW ARE TWITTER.. strukturu, da je mrežna struktura following-follower povezana sa strukturom reply-mention i da su reply-mention i co-tweet mreže pozitivno povezane. Rezultati također upućuju na to da su aktivne mrežne strategije kriptovaluta utjecale na njihove kreditne ocjene i, što je još važnije, da kriptovalute koje se češće povezuju sa srodnim valutama obično imaju visoke kreditne ocjene.

Ključne riječi: kriptovaluta, Twitter, analiza društvenih mreža, Weissov rejting, analiza sentimenta

\section{(c) $(1)$ (8)}

Međunarodna licenca / International License:

Imenovanje-Nekomercijalno/ Attribution-NonCommercial 